\title{
Radiosurgery for Epidermoid Tumors: Dramatic Pain Relief from Trigeminal Neuralgia
}

Yoshihisa Kida $^{1}$, Yoshimasa Mori ${ }^{2,}$ 3, 4, 5

1. Neurosurgery, Ookuma Hospital, Nagoya, JPN 2. Radiation Oncology and Neurosurgery, Shin-Yurigaoka General Hospital, Kawasaki, JPN 3. Neurological Surgery, Ookuma Hospital, Nagoya, JPN 4. Neurological Surgery, Aoyama General Hospital, Toyokawa, JPN 5. Radiology and Radiation Oncology, Aichi Medical University, Nagakute, JPN

Corresponding author: Yoshihisa Kida, yoshihisa_kida@mac.com

\section{Abstract \\ Purpose}

The purpose of this study is to discuss the long-term effects of radiosurgery for epidermoid tumors, including the symptoms of trigeminal neuralgia and/or facial spasm, which we have originally reported before.

\section{Background}

Intracranial epidermoids are slow-growing tumors that can become symptomatic once they develop into large tumors. The mainstay of the treatment is surgery. However, eradicating the whole tumor is often difficult and some tumors may recur. In addition to their mass effects on the brain, these tumors are often associated with hyperactive nerve dysfunction syndromes such as trigeminal neuralgia, glossopharyngeal neuralgia, and/or facial spasm.

\section{Cases and methods}

We report 13 cases of epidermoid tumors, 12 of which were located in the cerebellopontine angle (CPA), which were treated using 14 radiosurgery procedures. The inclusion criteria for radiosurgery were the presence of well-localized small tumors and/or severe associated neuralgia or facial spasms. The mean target volume ranged from 0.17 to $9.5 \mathrm{~cm}^{3}$ with a mean of $2.85 \mathrm{~cm}^{3}$. The lesions were treated with a mean maximum and a marginal dose of $28.2 \mathrm{~Gy}$ and $14.2 \mathrm{~Gy}$, respectively.

\section{Results}

Among the 14 gamma knife procedures that were performed in 13 patients, dose planning to ensure total and partial coverage for relief from hyperactive cranial nerve dysfunction (HCND) was performed. Six cases were totally and another eight were partially covered at the dose planning. The irradiated tumors showed a minor decrease or no remarkable changes during a mean follow-up period of 86.1 months. Tumor

Received 10/14/2019

Review began 11/07/2019 Review ended 12/12/2019 Published 12/23/2019

\section{() Copyright 2019}

Kida et al. This is an open access article distributed under the terms of the Creative Commons Attribution License CC-BY 3.0., which permits unrestricted use, distribution, and reproduction in any medium, provided the original author and source are credited. progression requiring a second surgery was seen in two cases. The trigeminal neuralgias either improved or disappeared soon after the procedure, enabling the discontinuation of the medication.

\section{Conclusion}

Radiosurgery led to a dramatic improvement in HCND. In fact, the immediate cure of neuralgia after the radiosurgery was observed in several cases, even after partial coverage with radiosurgery. The interface between the tumor and the nerve was the main target. The definite mechanisms for this favorable outcome have not been verified yet, but the functional modulation by the radiosurgery could be one.

Electrophysiological alteration at the interface between the tumor and nerve has been considered. When the tumors were totally covered with radiosurgery, persistent tumor control was expected. Sufficient tumor control is possible if the tumor can be covered entirely with radiosurgery. Functional modulation of trigeminal neuralgia and facial spasms can also be attained even by partial dose planning for the nervetumor interface.

Categories: Neurology, Radiation Oncology, Neurosurgery

Keywords: epidermoid, facial spasm, gamma knife, radiosurgery, trigeminal neuralgia

\section{Introduction}

Epidermoid tumors are generally slow-growing tumors. They are thought to develop between the third and fifth weeks of gestation from ectodermal remnants during neural tube formation in embryogenesis. Intracranial epidermoid tumors account for $1-2 \%$ of the reported intracranial tumors [1]. These tumors may be found chiefly in and around the cerebellopontine angle (CPA) or parasellar region. Since the tumors grow very slowly or are often indolent, they have typically developed into moderately large tumors by the time of 
their discovery. They become symptomatic by compressing the surrounding brainstem or stimulating nearby cranial nerves.

Besides the mass effects of brain compression caused by these tumors, epidermoids often cause hyperactive cranial nerve dysfunction (HCND) such as trigeminal or glossopharyngeal neuralgias or facial spasms [2,3]. Cranial nerve involvements often require adequate and prompt resolution to relieve these troublesome symptoms. Chemical meningitis is another special manifestation of this tumor, which is caused by the possible leakage of accumulated keratin and cholesterol inside the cyst into the subarachnoid space.

The mainstay of current treatments is surgical resection, but total resection of the tumors is often difficult and often hazardous because of the possible damages to the brain or cranial nerves, especially when the tumor capsule is firmly attached to cranial nerves or the brainstem $[4,5]$. Since our own first report on the treatment of epidermoid tumors using radiosurgery, several other clinical reports have been presented in which the successful resolution of HCND has been emphasized [6,7-10]. Here, we discuss the long-term clinical results of epidermoid tumors treated with radiosurgery. The purview of our report extends beyond tumor control and consider functional outcomes such as trigeminal neuralgia as well [11].

\section{Materials And Methods}

\section{Case selection}

Epidermoid tumors usually develop into large tumors that extend widely into the cerebral cisterns or into the cistern on the opposite side. Consequently, treatment with radiosurgery is often difficult and surgical resection is usually the preferred treatment method. Only patients with small well-localized tumors with a mean dimeter of less than $30 \mathrm{~mm}$ are considered suitable candidates for radiosurgery with full coverage of the tumor volume. In addition, patients suffering from HCND such as severe trigeminal or glossopharyngeal neuralgias or facial spasms and large epidermoid tumors in CPA are sometimes considered for radiosurgery, with the intention of pain relief and partial coverage of the nerve and tumor in the cistern.

Here, we report 13 cases of epidermoid tumors treated with 14 radiosurgery procedures (two radiosurgical procedures were required in one case). There were six males and seven females, and these epidermoid tumors accounted for less than $1 \%$ of the brain tumors encountered during 20 years of the study period at our institute. The patients' ages ranged from 7 to 80 years with a mean age of 47.2 years. The results of 14 trials of radiosurgery were summarized. Patients were suffering from trigeminal neuralgia in nine cases and/or facial spasm in two. HCND was recorded as the main neurological sign or as a single symptom (Table 1). In fact, many of the patients had either trigeminal neuralgia or facial spasms, at the same time or at different times during their clinical course. Other neurological deficits such as ataxia, diplopia, or hearing loss were also recorded. The locations of the lesions were exclusively within the CPA in 12 cases and within the interhemispheric cistern and pineal gland in one case each. Seven cases underwent surgical resection before radiosurgery to remove tumors and to obtain a histological diagnosis. The other seven cases were only diagnosed based on radiological studies such as CT scan or MRI. CT images showed a deep low-density spot while MRI showed an iso-intensity on T1 images and a high signal intensity on T2 images. First imaging steady-state acquisition (FIESTA) or heavy-T2 studies produced unique and specific images in the cerebral cisterns as shown in Figure 1. 


\section{Cureus}

\begin{tabular}{|c|c|c|c|c|}
\hline No & Age (years) & Sex & Symptom & Location \\
\hline 1 & 42 & $\mathrm{M}$ & Facial spasm & CPA \\
\hline 2 & 45 & $M$ & Trigeminal neuralgia & CPA \\
\hline 3 & 39 & $\mathrm{~F}$ & Trigeminal neuralgia & CPA \\
\hline 4 & 23 & $\mathrm{~F}$ & Diplopia & Pineal \\
\hline 5 & 43 & $\mathrm{~F}$ & Trigeminal neuralgia & CPA \\
\hline 6 & 46 & $\mathrm{M}$ & Trigeminal neuralgia & CPA \\
\hline 7 & 65 & $\mathrm{M}$ & Trigeminal neuralgia & CPA \\
\hline 8 & 80 & $\mathrm{~F}$ & Trigeminal neuralgia & CPA \\
\hline 9 & 7 & $\mathrm{~F}$ & Hearing loss & CPA \\
\hline 10 & 53 & $\mathrm{M}$ & None & Frontal base \\
\hline 11 & 30 & $\mathrm{~F}$ & Trigeminal neuralgia & CPA \\
\hline 12 & 66 & $\mathrm{M}$ & Trigeminal neuralgia & CPA \\
\hline 13 & 53 & $\mathrm{M}$ & Trigeminal neuralgia & CPA \\
\hline 14 & 69 & $\mathrm{~F}$ & Facial spasm & CPA \\
\hline Mean and total & 47.2 & M: 7; F: 7 & Trigeminal neuralgia: 9 ; facial spasm: 2 & CPA: 12; frontal: 1 ; pineal: 1 \\
\hline
\end{tabular}

\section{TABLE 1: Characteristics of cases treated with gamma knife surgery}




\section{Cureus}

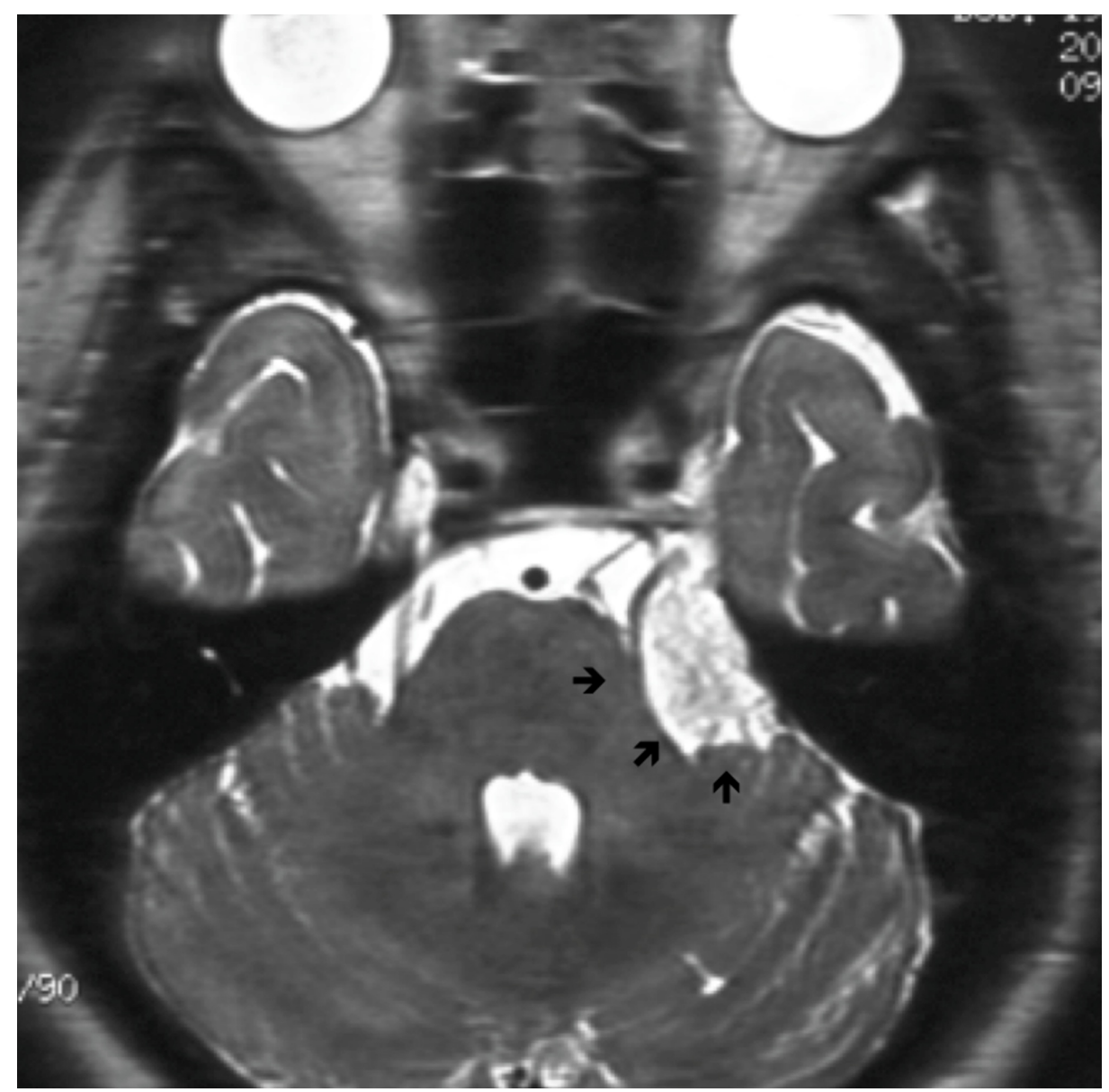

FIGURE 1: Characteristics of cases treated with gamma knife surgery

Most of the tumors were located exclusively in or around cerebellopontine angle (arrows)

\section{Radiosurgery}

Gamma knife treatment was performed under local anesthesia supplemented with intravenous anesthesias, and a Leksell head frame was used to stabilize the head of each patient. Enhanced T1 and T2 MRI images were obtained for dose planning with GammaPlan (ELEKTA, Stockholm). Coregistered FIESTA or heavy T2 studies were mainly used for dose planning to visualize all the tumor extensions into the cisterns. Two methods of radiosurgery were chosen. If the tumor was not large and well localized, the whole tumor was covered with radiosurgery (Figure 2). 


\section{Cureus}

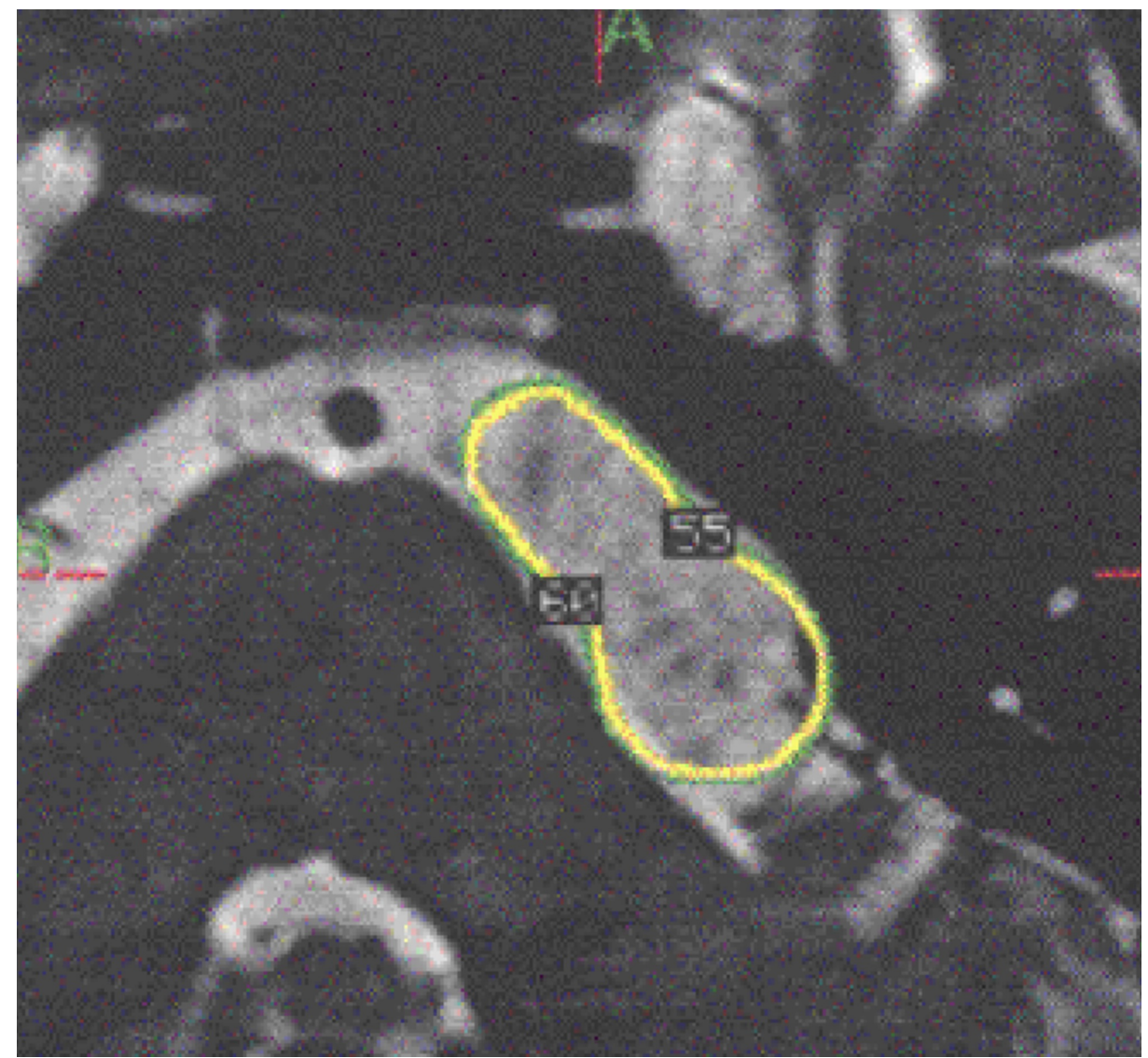

FIGURE 2: Whole tumor coverage at the radiosurgery

Yellow line indicates the tumor margin and the target volume

If, however, the tumor extended widely into the surrounding cisterns, only parts of the tumor that were circumscribed and had adhered to near-by cranial nerves in the cisterns were targeted with the intention of alleviating HCND symptoms such as trigeminal neuralgia and facial spasms (Figure 3). Dose planning was performed using GammaPlan (ELEKTA, Stockholm).

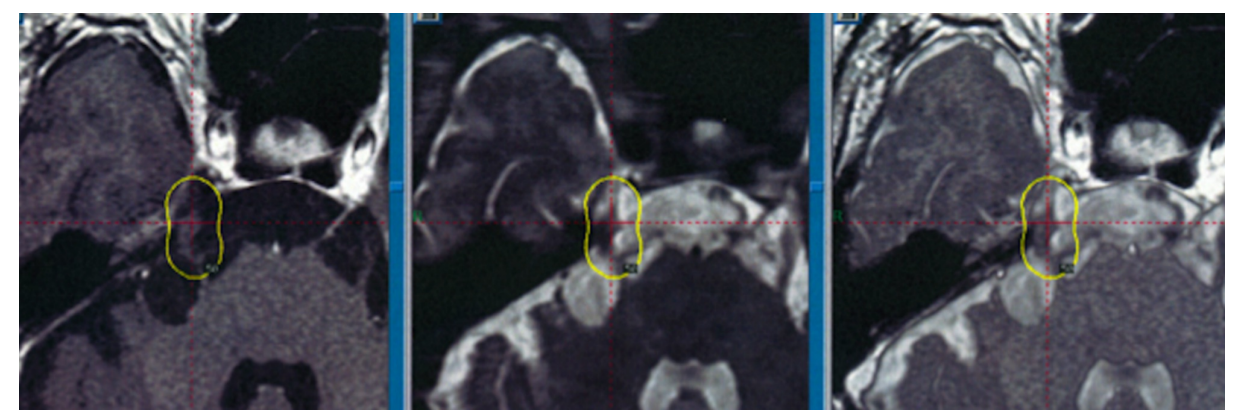

FIGURE 3: Partial tumor coverage

\section{Follow-up studies}

Medical follow-up studies consisting of neurological status assessments as well as imaging studies with enhanced MRI were performed every three months during the first year, and every six months thereafter. Trigeminal neuralgias are estimated with both a visual analog scale and demonstrated with a percentage decrease or increase of neuralgia with self-assessment by the patient and visual analog scale. Pain before and after gamma knife surgery was also evaluated retrospectively based on medical records using the Barrow Neurological Institute (BNI) pain intensity scale and the medication requirements.

\section{Statistical analyses}


Statistical analyses were performed using the t-test for the comparisons of paired data between the treatments with whole or partial coverage. A p-value of less than 0.05 was considered to be statistically significant.

\section{Results}

The tumors, which had a mean volume of $2.85 \mathrm{cc}$, were treated using either whole (seven cases) or partial tumor coverage (seven cases) with a mean marginal dose of $13.1 \mathrm{~Gy}$. The majority of tumors showed no apparent volume changes, however, some tumors demonstrated shrinkage. The improvements in HCND were remarkable even without medication. The details of the treatment with radiosurgery are summarized in Table 2 .

\begin{tabular}{|c|c|c|c|c|c|c|}
\hline $\begin{array}{l}\text { Neurological } \\
\text { Signs }\end{array}$ & Location & $\begin{array}{l}\text { Tumor } \\
\left(\mathrm{cm}^{3}\right)\end{array}$ & $\begin{array}{l}\text { Max D } \\
\text { (Gy) }\end{array}$ & $\begin{array}{l}\text { Marg D } \\
\text { (Gy) }\end{array}$ & Coverage & $\begin{array}{l}\text { Tumor } \\
\text { response }\end{array}$ \\
\hline 1. Facial spasm & CPA & 1.09 & 28 & 14 & Partial & PG \\
\hline $\begin{array}{l}\text { 2. Trigeminal } \\
\text { neuralgia }\end{array}$ & CPA & 0.52 & 24 & 14.6 & Partial & PG \\
\hline $\begin{array}{l}\text { 3. Trigeminal } \\
\text { neuralgia }\end{array}$ & CPA & 2.29 & 30 & 15 & Partial & NC \\
\hline 4. Diplopia & CPA & 9.5 & 26 & 13 & Partial & NC \\
\hline $\begin{array}{l}\text { 5. Trigeminal } \\
\text { neuralgia }\end{array}$ & CPA & 5.78 & 21 & 12.6 & Whole & PR \\
\hline $\begin{array}{l}\text { 6. Trigeminal } \\
\text { neuralgia }\end{array}$ & CPA & 1.5 & 28 & 14 & Partial & NC \\
\hline $\begin{array}{l}\text { 7. Trigeminal } \\
\text { neuralgia }\end{array}$ & CPA & 1.09 & 28 & 14 & Partial & NC \\
\hline $\begin{array}{l}\text { 8. Trigeminal } \\
\text { neuralgia }\end{array}$ & CPA & 2.51 & 28 & 14 & Whole & NC \\
\hline 9. Hearing loss & CPA & 1.13 & 23 & 16.1 & Whole & PR \\
\hline 10. None & Interhemispheric cistern & 3.7 & 28 & 14 & Whole & PR \\
\hline $\begin{array}{l}\text { 11. Trigeminal } \\
\text { neuralgia }\end{array}$ & CPA & 1.64 & 28 & 14 & Partial & NC \\
\hline $\begin{array}{l}\text { 12. Trigeminal } \\
\text { neuralgia }\end{array}$ & CPA & 0.82 & 23.3 & 14 & Whole & NC \\
\hline $\begin{array}{l}\text { 13. Trigeminal } \\
\text { neuralgia }\end{array}$ & CPA & 6.48 & 25 & 12.5 & Whole & PR \\
\hline 14. Facial spasm & CPA & 0.17 & 24 & 12 & Whole & NC \\
\hline Total or mean & $\begin{array}{l}\text { CPA: } 13 \text { cases; Interhemispheric cistern: } 1 \\
\text { case }\end{array}$ & 2.85 & 26 & 13.1 & $\begin{array}{l}\text { Whole: } 7 \\
\text { Partial: } 7\end{array}$ & $\begin{array}{l}\text { PR: 4; NC: 8; } \\
\text { PG: } 2\end{array}$ \\
\hline
\end{tabular}

\section{TABLE 2: Radiosurgery for epidermoid tumors and clinical follow-up results}

CPA: cerebellopontine angle; Max D: maximum dose; Marg D: marginal dose; PR: partial remission; NC: no change; PG: progression

Target volumes of the radiosurgery ranged from 0.17 to $9.5 \mathrm{~mm}^{3}$ with a mean of $2.85 \mathrm{~mm}^{3}$. After the radiosurgery, the hyperactive cranial nerve symptoms improved relatively fast, sometimes dramatically. In several cases, the trigeminal neuralgia disappeared shortly after radiosurgery, sometimes within a month. In fact, most of the trigeminal neuralgia improved or totally disappeared. Moreover, functional control or recovery was maintained for a long time as shown in Table 3. The prompt relief of neuralgia was achieved in 


\section{Cureus}

many cases. Facial spasms also improved in two cases. No further medications for neuralgia and facial spasm were not required in nine patients during 86 months after radiosurgery. In the majority of cases suffering from trigeminal neuralgia, the carbamazepine medication was discontinued shortly after radiosurgery in nine cases.

\begin{tabular}{|c|c|c|c|c|}
\hline No & $\begin{array}{l}\text { Age, } \\
\text { years }\end{array}$ & $\begin{array}{l}\text { Early response for } \\
\text { HCND }\end{array}$ & $\begin{array}{l}\text { Disappearance of HCND (months after } \\
\text { radiosurgery) }\end{array}$ & $\begin{array}{l}\text { Medication/last follow-up, } \\
\text { months }\end{array}$ \\
\hline 1 & 42 & 6 months & Yes (12) & No/168 \\
\hline 2 & 45 & 3 months & Yes (12) & No/168 \\
\hline 3 & 39 & months & Yes (7) & No/204 \\
\hline 4 & 23 & None & Diplopia & NC \\
\hline 5 & 43 & 1 month & Yes (1) & No/135 \\
\hline 6 & 46 & 8 months & Yes (8) & No/15 \\
\hline 7 & 65 & 8 months & $\operatorname{Re}$ & $\operatorname{Re}$ \\
\hline 8 & 80 & 1 month & Yes (12) & No/86 \\
\hline 9 & 7 & None & Hearing loss & NC \\
\hline 10 & 53 & None & No deficit & NC \\
\hline 11 & 30 & 6 months & Yes (12) & Yes/12 \\
\hline 12 & 66 & 1 month & Yes (1) & No/29 \\
\hline 13 & 53 & 1 month & Yes (1) & No/20 \\
\hline 14 & 69 & 1 month & Yes (1) & No/24 \\
\hline Total & ----- & Yes: 11; None: 4 & Yes (10) & No/9 \\
\hline Mean & 47.2 & ---- & ----- & Mean follow-up: 86.1 months \\
\hline
\end{tabular}

\section{TABLE 3: Summary of the follow-up results for HCND after radiosurgery}

HCND: hyperactive cranial nerve dysfunction; Re: recurrence of trigeminal neuralgia; NC: no change

Tumor control was evaluated using serial MRI studies. In cases with whole tumor coverage, the tumor control was excellent, demonstrating a sufficient tumor shrinkage without any signs of tumor progression (Figure 4).
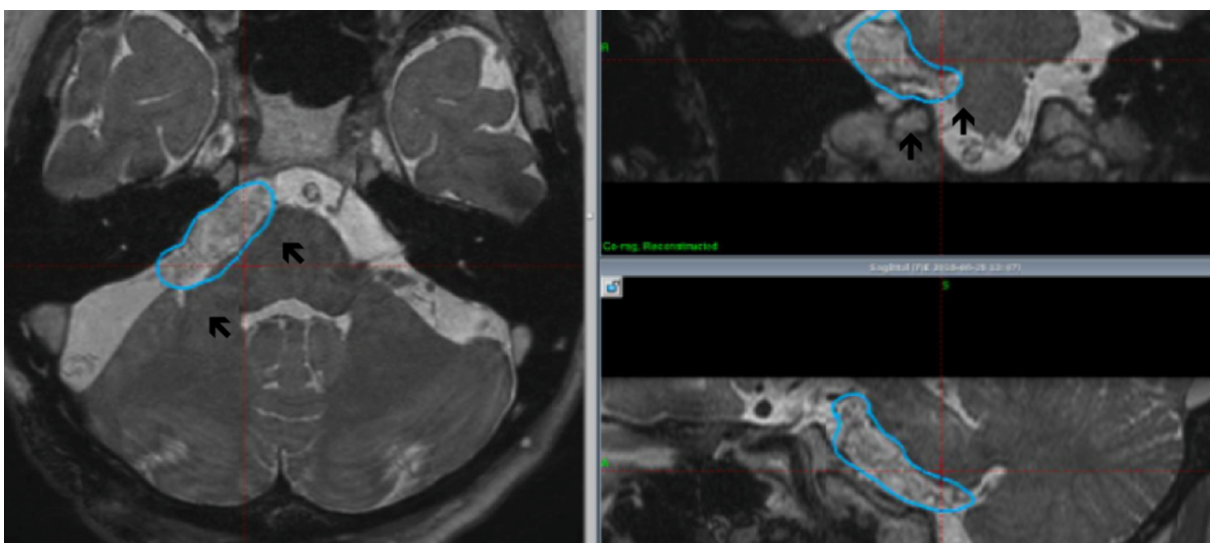

FIGURE 4: Whole tumor coverage (six months after radiosurgery)

Apparent tumor shrinkage was observed (arrows) in some cases. The blue line indicates the tumor margin that was treated using gamma knife surgery 
In cases with partial tumor coverage, only minor and partial tumor shrinkage was observed. However, because of tumor regrowth, subsequent tumor resection was required in two cases that had been treated with partial tumor coverage. Early relief from trigeminal neuralgia was achieved in seven cases. Facial spasms of the two cases also improved consistently within a few months and totally disappeared within one year after the procedure. No serious complications have occurred to date. Subsequent tumor resections were required in two cases because of tumor progression, but only in cases with partial tumor coverage. No perifocal edema associated with neurological signs was encountered.

\section{Discussion}

Epidermoid tumors grow very slowly and have been reported to disappear spontaneously within several years. They often cause no neurological deficits even after developing into large tumors, chiefly in the CPA. However, they often become symptomatic because of cranial nerve involvements in the CPA or due to the direct compression of the cerebellum and brainstem. In fact, many cases suffer from HCND, including trigeminal or glossopharyngeal neuralgias as well as facial spasms [2,3]. The incidence of HCND is very high among cases of epidermoid tumors as the trigeminal or facial nerves are often involved and distorted with or without strangulation of the nerve inside the tumor. Abnormal compression or strangulation by the tumor is common and speculated to be the direct cause of such symptoms [4,5]. Spontaneous hemorrhage or chemical meningitis caused by the leakage of the cyst contents has been also reported in the past. These debilitating symptoms apparently may require some form of treatment.

The mainstay of the treatment for this tumor is surgical tumor resection $[4,5]$. Despite the recent developments in microsurgery in and around the skull base, the surgical management of epidermoid tumors that are strongly attached to pia, arachnoid membrane or brainstem is extremely challenging because these tumors grow in close contact with cranial nerves and vascular structures that are often firmly attached to the arachnoid, cranial nerves or to brainstem. Extensive surgery may be associated with severe neurological sequelae, such as cranial nerve dysfunctions or brainstem damages.

Previous reports have shown that HCND, including trigeminal neuralgia and facial spasms, is more common in epidermoid tumors than in other CPA tumors such as meningiomas, schwannomas, or malignant skull base tumors $[8,10,12]$. Trigeminal nerves are often encased within an epidermoid tumor and the cholesterol materials that are produced by the tumor, and thus are more likely to be influenced or stimulated than in situations where only tumor compression is present.

Prior to the advent of the operating microscope, the operative morbidity and mortality rates reportedly ranged from $20 \%$ to $57 \%$. Although contemporary series have reported lower operative mortality rates, the morbidity rate for cranial nerves or brain structures continues to be an issue. Surgical removal of the tumor's content is not difficult, but the resection of the tumor capsule, firmly attached to the brainstem or cranial nerves, is often harmful [4,5]. The rates of complete and incomplete resections have been inconsistent and the recurrence rates are not significantly different between these two groups. Serious adverse effects that impact the lower cranial nerves and brainstem can cause difficulty with swallowing and respiration.

Several clinical trials of standard fractionated radiotherapy for epidermoid tumors have been reported in the past with favorable results [13]. However, malignant transformation or the occurrence of squamous carcinomas has been reported after radiotherapy $[14,15]$. Radiosurgery trials for the management of epidermoid tumors have been reported in the literature (Table 4 ) $[6,7,9]$. Targets of radiosurgery were either tumor, nerve, or the interface. Successful improvement of trigeminal neuralgias and facial spasms was reported. Since these tumors have usually expanded widely over the surface of the brainstem and have often adhered to the surrounding brain tissue, radiosurgery can be difficult. 


\section{Cureus}

\begin{tabular}{|c|c|c|c|c|c|}
\hline Reporter & Cases & Method & $\begin{array}{l}\text { Dose, } \\
\text { Gy }\end{array}$ & Response & Remarks \\
\hline $\begin{array}{l}\text { 1. Kida et al. } \\
\text { [6] }\end{array}$ & 7 (6 CPA) & $\begin{array}{l}\text { Partial or } \\
\text { total }\end{array}$ & 14.6 & No neuralgia (4/4) & $\begin{array}{l}\text { Neuralgia disappeared; } \\
\text { radiosurgical nerve decompression } \\
\text { suspected }\end{array}$ \\
\hline $\begin{array}{l}\text { 2. Cho KR et } \\
\text { al. [8] }\end{array}$ & $\begin{array}{l}\text { Meningioma: 30; } \\
\text { schwannoma 18; } \\
\text { Epidermoid: 1; AVM: } 1\end{array}$ & $\begin{array}{l}\text { At } \\
\text { fifth nerve } \\
\text { root }\end{array}$ & 90 & $\begin{array}{l}\text { BNI score improved from } \\
3 \text { to } 2\end{array}$ & Tumor size unchanged \\
\hline $\begin{array}{l}\text { 3. El-Shehaby } \\
\text { et al. [9] }\end{array}$ & 12 cases (15 sessions) & $\begin{array}{l}\text { Tumor } \\
\text { fifth nerve } \\
\text { root }\end{array}$ & $\begin{array}{l}11, \\
90\end{array}$ & $\begin{array}{l}\text { Neuralgia disappeared } \\
\text { (5); facial spasm resolved } \\
(2 / 2)\end{array}$ & $\begin{array}{l}\text { Tumor size unchanged or shrank in } \\
1\end{array}$ \\
\hline $\begin{array}{l}\text { 4. Vasquez } \\
\text { JAJ et al. [7] }\end{array}$ & 4 cases & $\begin{array}{l}\text { Tumor } \\
\text { fifth nerve }\end{array}$ & $\begin{array}{l}15 \\
80\end{array}$ & Neuralgia improved & $\begin{array}{l}\text { Good and safe alternative to } \\
\text { microsurgery }\end{array}$ \\
\hline $\begin{array}{l}\text { 5. Present } \\
\text { series, Kida } \\
\text { et al. }\end{array}$ & 13 cases (14 sessions) & $\begin{array}{l}\text { Tumor and } \\
\text { nerve } \\
\text { interface }\end{array}$ & 13.1 & $\begin{array}{l}\text { Neuralgia facial spasm } \\
\text { disappeared }\end{array}$ & Tumor control in $12 / 14$ cases \\
\hline
\end{tabular}

TABLE 4: Current radiosurgical trials for the management of epidermoid tumors

In our treatment series, well-localized epidermoid tumors that were recognized using imaging studies responded well to radiosurgery. More importantly, prompt relief from trigeminal neuralgia and facial spasms were achieved using radiosurgery with a much lower radiation dose than that was required for the radiosurgery for classical trigeminal neuralgia. Moreover, the effects of pain control appeared very quickly after the procedure and were persistent and sustainable for a very long time. In fact, most of the cases did not require any further medication for neuralgia or facial spasms. Other CPA tumors, such as meningiomas and schwannomas, are sometimes associated with trigeminal neuralgia. The main cause of neuralgias appears to be the mass effects on the nerves, and the alleviation of such symptoms is often difficult without surgery.

In general, radiosurgery is known to have strong effects on the creation of intimal hypertrophy of arteriovenous malformation (AVM) vessels and the growth control of both benign and malignant brain tumors cells. Radiosurgery is believed to create a power of lesioning in the brain tissue to improve movement disorders and essential tremors. In the present series, radiosurgery for the treatment of epidermoid tumors utilized a different mechanism. First of all, trigeminal neuralgia can be specifically relieved using a low radiosurgical dose of less than $15 \mathrm{~Gy}$ at the margin; however, this dose would be insufficient to alleviate classical trigeminal neuralgia. Of importance, relief from neuralgia can be achieved very quickly after radiosurgery and can be sustained for a very long time as demonstrated in our series. Therefore, another kind of mechanism such as functional modulation may contribute to pain relief and the control of facial spasms. Mechanical decompression or the correction of nerve kinking might occur after radiosurgery-induced tumor shrinkage. However, such mechanisms were not apparent in our cases. Second, a decreased compression with offending vasculature around the nerve exit zone may happen. Again these mechanisms were not consistent with the findings in our cases. Finally, a decreased chemical stimulation with cholesterol materials or altered electrophysiological conditions at the nerve entry zone may be considered. The functional control for HCND, facial spasm, and trigeminal neuralgia is something unique as it works very quickly and consistently after the procedure. The theoretical basis of these effects has not yet been verified. The generation of abnormal discharges inside the nerve at the interface of the nerve and epidermoid tumor in the cistern may cause hyperactive cranial nerve dysfunction. Therefore, the irradiation of the interface using radiosurgery might alter this abnormal electrophysiological condition and stop the abnormal electrical discharges in the cranial nerves.

We previously reported on the successful pain control of trigeminal neuralgia associated with epidermoid tumor in 2006 [6]. Since then, only a few reports on different radiosurgery methods have been published $[7,9]$.

\section{Future strategy for the management of epidermoid tumor}

The mainstay of treatment for epidermoid cysts continues to be surgery. However, radiosurgical procedures seem to be very useful for the alleviation of HCND. If a tumor is small and well-localized, tumor control can also help to alleviate associated neuralgia symptoms. Thus, radiosurgery might be a useful tool for managing residual or recurrent tumors after surgery. More importantly, radiosurgery can be used to achieve functional control or functional modulation. 


\section{Conclusions}

Epidermoid tumors are particularly sensitive to radiosurgery. In fact, tumor control after the treatment is often favorable and tumor shrinkage can be achieved when the tumor is properly covered within the target volume. However, tumors with large volumes are difficult to cover completely. In conclusion, radiosurgery might be favored for epidermoid tumors when they are small and localized. Radiosurgery might also be suitable for residual tiny or thin-slice tumors or recurrent tumors after surgery. From a functional point of view, prompt relief from trigeminal neuralgia and other hyperactive nerve dysfunctions are especially beneficial to patients. Therefore, radiosurgery appears to be a very useful treatment for patients suffering from intractable trigeminal neuralgias and facial spasms associated with epidermoid tumors.

\section{Additional Information \\ Disclosures}

Human subjects: Consent was obtained by all participants in this study. IRB of Ookuma Hospital issued approval 51. Animal subjects: All authors have confirmed that this study did not involve animal subjects or tissue. Conflicts of interest: In compliance with the ICMJE uniform disclosure form, all authors declare the following: Payment/services info: All authors have declared that no financial support was received from any organization for the submitted work. Financial relationships: All authors have declared that they have no financial relationships at present or within the previous three years with any organizations that might have an interest in the submitted work. Other relationships: All authors have declared that there are no other relationships or activities that could appear to have influenced the submitted work.

\section{References}

1. Sabin HI, Bordi LT, Symon L: Epidermoid cysts and cholesterol granulomas centered on the posterior fossa: twenty years of diagnosis and management. Neurosurgery. 1987, 21:798-805. 10.1227/00006123198712000-00004

2. Kobata H, Kondo A, Iwasaki K: Cerebellopontine angle epidermoids presenting with cranial nerve hyperactive dysfunction: pathogenesis and long-term surgical results in 30 patients. Neurosurgery. 2002, 50:276-285. 10.1097/00006123-200202000-00008

3. Kobata H, Kondo A, Iwasaki K, Nishioka T: Combined hyperactive dysfunction syndrome of the cranial nerves: trigeminal neuralgia, hemifacial spasm, and glossopharyngeal neuralgia: 11-year experience and review. Neurosurgery. 1998, 43:1351-1361. 10.1097/00006123-199812000-00052

4. Hasegawa M, Nouri M, Nagasaki S, et al.: Cerebellopontine angle epidermoid cysts: clinical presentations and surgical outcome. Neurosurg Rev. 2016, 39:259-266. 10.1007/s10143-015-0684-5

5. Schiefer TK, Link MJ: Epidermoid of the cerebellopontine angle: a 20-year experience . Surg Neurol. 2008, 70:584-590. 10.1016/j.surneu2007.12.021

6. Kida Y, Yoshimoto M, Hasegawa T, Fujitani S: Radiosurgery of epidermoid tumors with gamma knife: possibility of radiosurgical nerve decompression. (Article in Japanese). No Shinkei Geka. 2006, 34:375-381.

7. Vasquez JA, Fonnegra JR, Diez JC, Fonnegra A: Treatment of epidermoid tumors with radiosurgery: case series. Surg Neurol Int. 2016, 7:S116-120. 10.4103/2152-7806.176132

8. Cho KR, Lee MH, Im YS, Kong DS, Seol HJ, Nam DH, Lee JI: Gamma knife radiosurgery for trigeminal neuralgia secondary to benign lesions. Headache. 2016, 56:883-889. 10.1111/head.12801

9. El-Shehaby AMN, Reda WA, Karim KMA, Eldin RME, Nabeel AM: Gamma knife radiosurgery for cerebellopontine angle epidermoid tumors. Surg Neurol Int. 2017, 8:258. 10.4103/sni.sni_206_17

10. Neff BA, Carlson ML, O’Byrne MM, Van Gompel JJ, Driscoll CLW, Link MJ: Trigeminal neuralgia and neuropathy in large sporadic vestibular schwannomas. J Neurosurg. 2017, 127:992-999. 10.3171/2016.9.JNS16515

11. Rogers CL, Shetter AG, Fiedler JA, Smith KA, Han PP, Speiser BL: Gamma knife radiosurgery for trigeminal neuralgia: the initial experience of The Barrow Neurological Institute. Int J Radiat Oncol Biol Phys. 2000, 47:1013-1019. 10.1016/s0360-3016(00)00513-7

12. Phan J, Pollard C, Brown PD, et al.: Stereotactic radiosurgery for trigeminal pain secondary to recurrent malignant skull base tumors. J Neurosurg. 2018, 130:812-821. 10.3171/2017.11.JNS172084

13. Davies JM, Trinh VT, Sneed PK, McDermott MW: Radiotherapy for recurrent epidermoid cyst . J Neurooncol. 2013, 112:307-313. 10.1007/s11060-013-1065-y

14. Link MJ, Cohen PL, Breneman JC, Tew JM Jr: Malignant squamous degeneration of a cerebellopontine angle epidermoid tumor. Case report. J Neurosurg. 2002, 97:1237-1243. 10.3171/jns.2002.97.5.1237

15. Mori Y, Suzuki Y, Tanasawa T, Yoshida J, Wakabayashi T, Kobayashi T: A case report of epidermoid carcinoma in the cerebello-pontine angle. (Article in Japanese). No Shinkei Geka. 1995, 23:905-909. 